\title{
An alternative policy evaluation of the British Columbia carbon tax: broadening the application of Elinor Ostrom's design principles for managing common-pool resources
}

\author{
$\underline{\text { Karine Lacroix }}^{1}$ and Garrett Richards ${ }^{1}$
}

\begin{abstract}
Climate change is putting infrastructure, food supply, water resources, ecosystems, and human health at risk. These risks will be exacerbated depending on the degree of additional greenhouse gas emissions. Urgent action is needed to limit the severity of impacts associated with further warming. British Columbia (BC) has taken action to reduce greenhouse gas emissions from carbonbased fuels by introducing a carbon tax in 2008. As an innovative approach to climate change mitigation, especially in North America, studies evaluating its effectiveness are valuable. We assessed the long-term viability potential of the $\mathrm{BC}$ carbon tax using common pool resource design principles, a novel application of the design principles to environmental policy. We found that the design principles can be applied productively to environmental policy and larger scale air pollution problems. With regard to the BC carbon tax, our findings suggest that closer monitoring of user behavior, further increases of the tax over time, and pursuing efforts for a more elaborate system of nested enterprises and interjurisdictional cooperation could increase the long-term success of the $\mathrm{BC}$ carbon tax. We also found that the design principles allowed us to more comprehensively reach conclusions regarding the broader effectiveness of the tax when compared to existing policy analysis. Traditionally, climate policy evaluation has focused on the end goal without considering broader constraints and issues of resource allocation. We suggest that common pool resource theory, which is based on strong theoretical principles and encourages reflexivity, will be able to address those limitations.
\end{abstract}

Key Words: British Columbia carbon tax; common-pool resource; Elinor Ostrom design principles; policy analysis

\section{INTRODUCTION AND LITERATURE REVIEW}

Human-caused climate change is a global environmental challenge that is likely related to increases in atmospheric and ocean temperatures, rises in sea level, more frequent heat waves, and heavy precipitation events (IPCC 2013). To limit the impacts of climate change, societies must reduce their consumption of carbon-based fuels. Most economists agree that putting a price on carbon is the most viable approach to achieving a reduction in greenhouse gas (GHG) emissions (Elgie and McClay 2013). A recent study predicts that a carbon tax results in greater changes in consumption patterns than a fuel price increase caused by standard price fluctuation: a $5 \%$ increase in the market price of gasoline resulted in a $1.8 \%$ reduction in consumption, whereas the same increase caused by a carbon tax resulted in a $12.5 \%$ reduction (Rivers and Schaufele 2013).

Following a similar logic as Epstein et al. (2014), the research presented in this paper is based on the premise that the atmosphere and its role in regulating the Earth's climate can be studied through a common-pool resource (CPR) lens because the same underlying incentive structure applies; each individual benefits from polluting while the costs of the pollution are shared with others, which often leads to overuse problems as individuals behave opportunistically. CPRs are a type of good for which two conditions must be met: (1) it is nearly impossible to exclude individuals from consuming the resource, i.e., benefiting from it, and (2) use of the resource by one user subtracts from the availability of that resource to other users (Ostrom 1990). Two resources are part of this CPR system: the resource system (i.e., climate regularity, as opposed to climate change and the aforementioned risks) and the resource unit (i.e., pollutants in the form of GHG emissions). The first condition for CPR is met: individuals cannot realistically be excluded from consuming carbon-based fuels, nor can they be excluded from the benefits of climate regularity, or the loss associated with climate change. The second condition is met in principle: an individual's GHG emissions do not limit another individual's capacity to pollute (although one could argue that on a larger time-scale, it does, because carbon-based fuels are a limited resource), however, they do affect the stability of climate regularity for all users.

In CPR theory, Elinor Ostrom's (1990) design principles are a combination of variables that may affect or facilitate the likelihood of successfully managing a CPR, because they have been shown to be present in case studies where users have achieved joint benefits sustained over a long period. Although typically employed for the management of a natural resource, e.g., forests or fisheries, the CPR literature, including its design principles, is just starting to be applied to pollutants (see Epstein et al. 2014) and hence might provide insights to complement policy analyses. Our purpose is to conduct an alternative policy evaluation of the British Columbia (BC) carbon tax using Ostrom's design principles for managing CPRs. To achieve this, we reviewed the literature on the design principles for CPR management and policy evaluation, as well as existing analyses of the $\mathrm{BC}$ carbon tax. We selected BC's carbon tax as the case study for this endeavor because it has already undergone traditional empirical evaluations, but could benefit from further assessment because it is relatively new. We examine whether the design principles can help address shortcomings of existing BC carbon tax policy evaluations and be applied to large-scale CPRs. Specifically, through critical analysis of this documentation, we investigate the following questions: Are the design principles present in this governance system? Are they associated with reductions in carbon emissions, likely due to the carbon tax? 


\section{Literature review: common-pool resource theory}

Central to CPR theory is the recognition that collective action problems often are integral to environmental problems (Ostrom 2010). Collective action problems emerge when rational individual actions have costly collective impacts. Traditionally, the only perceived solution to problems of CPR management was to have an external regulatory body manage the resource, either directly or through the allocation of property rights, to prevent self-interested people from overusing the resource (Hardin 1968). However, CPR theory establishes that local users have the potential to self-organize and manage resources without external regulation (Ostrom 1990). This self-organization is relevant even to global resource issues, the managing of which requires action at all scales, i.e., polycentricity (see Agrawal 2002, Ostrom 2009, 2010, 2012). Of course, with large-scale CPR issues implicating a large group of users, high resource mobility, and a low degree of excludability (Agrawal 2001), organic self-organization is extremely challenging, perhaps impossible, so regulation and matters of policy or institutional design are very important.

A number of design principles for the effective management of CPRs have emerged from the work of Elinor Ostrom (1990). A design principle is defined as "an essential element or condition that helps to account for the success of these institutions in sustaining CPRs and gaining the compliance of generation after generation of appropriations to the rules in use" (Ostrom 1990:90). More specifically, these design principles, discussed in greater detail in the results section, suggest that clear boundaries should exist for users and resources, rules should be congruent with local conditions, benefits obtained from the resource should be proportional to inputs, stakeholders should be able to participate in modifying rules, accountable parties should monitor the use and condition of the resource, penalties for rulebreakers should be proportional, accessible and responsive conflict resolution mechanisms should be available, managing institutions should not be undermined by external governmental authorities, and management regimes should be nested within parallel regimes at other scales (Ostrom 1990, Cox et al. 2010).

The CPR design principles, however, have their own limitations: challenges in application to larger scales and a resource-centric focus. First, a review of 91 studies that examine the principles and their application to cases of CPR management finds that the small-scale resource regimes that embodied the principles were more likely to be successful than those that did not (Cox et al. 2010). We point out that many scholars question whether the design principles can be applied to larger-scale cases. So far little work has been done on larger-scale CPR systems (e.g., Rowland 2005, Cox 2014), but a number of the principles seem relevant across scales. Their application at larger scales is gaining recognition in the literature, as demonstrated by a special issue of the International Journal of the Commons dedicated to larger-scale CPR theory (Cox 2014). In that special issue, Fleischman et al. (2014) compared five large-scale CPR management cases. Overall, the authors find that five design principles seem to be important facilitators in the success of large-scale CPR management. However, the authors call for further case studies to assess the larger scale application of the design principles (Fleischman et al. 2014).

Second, CPR theory has been used conventionally to analyze institutions that manage a natural resource, e.g., fisheries, but it is also applicable to pollution problems, e.g., water pollution or GHG emissions, because they both have the same core problems of appropriation, i.e., one individual benefits from emitting a pollutant at the expense of the community, and provision, i.e., inability to exclude free riders (Epstein et al. 2014, VillamayorTomas et al. 2014). CPR theory has been applied to global climate change (Ostrom 2010, 2012). More specifically, the design principles have recently been applied to pollution problems, such as water pollution and ozone depleting substances (Epstein et al. 2014, Fleischman et al. 2014, Villamayor-Tomas et al. 2014). Epstein et al. (2014) studied the Montreal Protocol and its management of ozone depleting substances through the CPR theory lens. The Montreal Protocol is often seen as an international CPR management success. However, two design principles were found to be weak or absent in their case study, and as such, the authors suggest that resource boundaries and graduated sanctions might not correspond to pollution cases. However, the authors highlight the need for further research of large-scale pollution cases, which may provide additional insight. We suggest that attempting to apply the principles to a large-scale pollutant policy would help address the limitations of the CPR design principles.

\section{Literature review: policy evaluation}

Policy analysis is an academic and applied field that assesses the effectiveness of policies such as carbon taxes. It has a rich historical tradition in the academic disciplines of political science, public administration, and economics, and is also relevant to the activities of interest groups, think tanks, governments, nongovernment organizations, media outlets, and individual citizens. Theoretical analyses, common in academia, examine how a certain policy arose, while practical, applied analyses seek to assess the impacts of a policy and judge its effectiveness (Pal 1987, Howlett et al. 2009). In this paper, we concentrate on the latter, and use the terms "evaluation" and "analysis" interchangeably to refer to that kind of assessment. A policy evaluation can be as simple as reading a policy document and then assessing its internal consistency or consistency with other policies and social goals. Systematically conducted formal evaluations are commonly more empirical, measuring the impacts of a policy and comparing them to its goals to assess effectiveness (Pal 1987). Specifically, an empirical evaluation might ask whether a program fulfills its objectives, whether an alternative would have better met those objectives, whether the objectives are actually relevant to the problem, and whether the policy or goals have unintended consequences (Howlett et al. 2009); basically, it should provide some consideration of effectiveness, efficiency, and equity.

Many empirical evaluations have already been conducted on climate change policies, yet such assessments face challenges. Huitema et al. (2011), for instance, review 259 such evaluations in the European Union, also noting that effectiveness, efficiency, and equity are common criteria for evaluation. Moreover they find that good evaluations are expected to acknowledge the complexity of the problem, be reflexive, i.e., question the official goals, and incorporate stakeholders. However, their review finds a gap between theory and practice: most climate policy evaluations do not include stakeholders and, more importantly, are not very reflexive; they tend to focus mostly on basic considerations of effectiveness, e.g., did the policy meet its goal?, instead of broader issues like resource allocation, e.g., are other policy areas more worthwhile?, and systemic barriers, e.g., are 
fundamental changes to the system needed?. As such, the field of policy analysis still faces major challenges, especially when it comes to a complex issue like climate change.

The breadth of the policy analysis field, as well, can be a limitation because few "best practices" or "design principles" are able to emerge. Those that do exist, e.g., that policy institutions should be flexible, accountable, and aware of the incentives of various involved actors (see Goodin 1998), can, thus, seem insufficiently specific to provide guidance for a given case. Indeed, the broader institutional context or constitutional setting is very relevant, such that different types of institutional analysis are appropriate for different cases (Vatn 2005, Thiel 2014). For policy design and evaluation, no one-size-fits-all solution exists (Howlett et al. 2009), so it is important to investigate new and innovative analyses. We hypothesize that CPR theory might be able to address some of the gaps in the general field of policy evaluation and provide more specific guidance for a certain subset of policies, including climate change programs. Examining a policy for CPR design principles is not a standard evaluation - it does not explicitly and directly measure whether the policy met its goal. It does, however, check whether the policy follows established best practices. It is also more reflexive because the presence or absence of principles may reveal new reasons for success or failure, suggesting improvements not identified by traditional evaluations. We seek to supplement, rather than replace or supplant, the existing evaluations.

\section{METHODOLOGY, CASE STUDY, AND MATERIALS}

\section{Methodology and methods}

Our study falls within a broader literature looking at design principles and recognizes the analytical advantage in using a common structure as a starting point for the analysis, i.e., the design principles, to allow for more systematic comparisons (Young et al. 2006). At the same time, we recognize the unique nature of our case and interpret the principles in such a manner that specific insights for it will be generated (see Young 2002). This research complements existing research using similar methodology in the hopes that together, they will yield useful insights regarding the applicability of the design principles to larger-scale CPRs and pollution problems.

Using descriptive case study research methodology (Tellis 1997, Baxter and Jack 2008), we conduct an in-depth analysis exploring the relevance of the design principles to the $\mathrm{BC}$ carbon tax. We review the design principles literature to gather a description of each design principle and consider how they might theoretically apply to the carbon tax. Using the design principles to guide data collection through a process of "coding down" (see Lockyer et al. 2004), we conduct a document review of peer-reviewed journal databases, e.g., Web of Science, and government resources, e.g., Carbon Tax Act, Climate Action Plan, etc., to determine the absence, presence, or moderate presence of the design principles in our case (e.g., Design principle 1A: does the Carbon Tax Act have clear social boundaries?).

\section{Case study background: British Columbia carbon tax}

The BC Carbon Tax Act was implemented in July 2008 (BC Government 2013a). The main objective of a carbon tax is to provide an economic incentive for reduction in fossil-fuel use by individuals, businesses, industry, and governments. When carbonbased fuels are not taxed, uncompensated environmental effects of production and consumption result in market externalities in the form of GHGs (Sodero 2011). By putting a price on carbon fuels, this policy attempts to internalize the environmental costs associated with these fuels' GHG emissions and thus encourage behavioral changes (Litman 2009, Sumner et al. 2009). The end goal of the carbon tax is to directly manage pollutants, i.e., the resource unit, thus indirectly protecting a resource system that provides climate regulation. More specifically, according to the province's Climate Action Secretariat (BC Government 2008), the main principles of the tax are:

- all carbon tax revenue is to be recycled through tax reductions rather than fund government programs

- the tax rate started low and increased gradually in order to give individuals and businesses time to plan and adjust

- low-income individuals and families are to be protected through a refundable 'Low Income Climate Action Tax Credit'

- the tax has a broad base, applying to all emissions from fossil fuel combustion in $\mathrm{BC}$ captured by the national inventory report

- as it cannot meet BC's emission-reduction targets on its own, the tax will be integrated with other policy measures

\section{Existing policy analyses}

We analyzed three prior evaluations of the $\mathrm{BC}$ carbon tax. The first was conducted by the BC government as part of the 2013 budget process (see BC Government 2013a). It reviews the tax after its initial plan to increase the rate every year from 2008 to 2012 had been implemented. It is noteworthy that this review process involved substantial public input, considering submissions from about 2000 individuals and 100 organizations. Although the details of the review are not publicly available, summaries report primarily on the measured economic impacts of the tax: the tax had a small negative impact on the level and growth of economic output, though the impact varies by industry. The report also highlights the vulnerability of the agriculture and agri-food sectors, and points to minor exemptions and subsidies for those sectors, to be implemented as a result of the review. However, the evaluation concludes that there is an adequate level of public support for the tax. Overall, it addresses the standard evaluation criteria of efficiency and equity.

The second evaluation was conducted by a research network at the University of Ottawa called Sustainable Prosperity (SP), and is available to the public in its entirety (see Elgie and McClay 2013). It reports that per capita consumption of petroleum products in $\mathrm{BC}$, including motor gasoline, declined since the carbon tax was implemented, compared to historical trends and compared to the rest of Canada, i.e., a $17.4 \%$ reduction in $\mathrm{BC}$ over the period of 2008 to 2012, as opposed to a $1.5 \%$ increase in the rest of Canada. The province's GHG emissions also declined compared to the rest of Canada over the course of the tax, i.e., a $10 \%$ reduction in BC over the period of 2008 and 2011, compared to a $1.1 \%$ decrease in the rest of Canada. The SP report thus measures progress on the main goal of the carbon tax, although 
it acknowledges that only a strong correlation exists, rather than a conclusive causation. Furthermore, the report also examines economic effects, observing that there is no overall tax burden, i.e., the government has returned more money to the population in associated tax cuts than it has collected in carbon tax revenue, and that there appears to be no negative impact on economic growth, i.e., BC's economy kept pace with the rest of Canada during the carbon tax years. Finally, it speaks briefly about the disproportional impacts of the tax on vulnerable households, communities, and sectors. It highlights the targeted tax reductions, e.g., the "Low Income Climate Action Tax Credit" and rebates for northern and rural homeowners, that attempt to address such concerns as part of the policy. So the SP report evaluates all three of the standard criteria, i.e., effectiveness, efficiency, and equity, though it is a bit weak on the latter.

The third focuses on public and stakeholder perspectives of the carbon tax (see Rhodes and Horne 2013). It demonstrates that $\mathrm{BC}$ residents and stakeholders, e.g., local governments, energy companies, environmental organizations, and business organizations, support the carbon tax. Only 14\% of stakeholders want the tax to be reduced or eliminated, showing that a vast majority supports either maintaining or increasing the carbon tax rate. The proportion of stakeholders wanting the tax to be reduced coincided with the proportion that perceived negative consequences associated with the carbon tax, especially for small business competitiveness. Of the standard evaluation criteria, this review examines only equity.

Collectively, the existing policy evaluations on the carbon tax do an adequate job of assessing whether the policy met its goals, considering all three of the standard policy evaluation criteria (e.g., Effectiveness: Did emissions decrease? Efficiency: Did this happen efficiently, with a low economic cost? Equity: Were the impacts fair and did the public approve?). However, they do not directly ask broader questions regarding whether the policy conforms to best practices or in what future direction it should move. As stated above, it is not our goal to replace such evaluations, but to supplement them, by answering these very questions through the application of CPR theory.

\section{RESULTS}

\section{Design principles applied to the $\mathrm{BC}$ carbon tax}

Design principle 1A. User boundaries: clear boundaries between legitimate users and nonusers must be clearly defined (Table 4 in Cox et al. 2010).

This design principle stipulates that having well-defined community boundaries for a CPR increases the chances of management success. Thus, access rights for users and outsiders should be clearly outlined (Tucker 1999, Cox et al. 2010, Wilson et al. 2013). The carbon tax has clearly defined social boundaries; it applies to every individual or entity that is located within the boundaries of the Province of British Columbia, i.e., approximately 4.5 million residents (BC Stats 2013), plus nonresidents if they purchase carbon-based fuel while they are within provincial boundaries. However, the carbon tax does not apply to BC residents if they purchase fuel while outside of the province; it is applied strictly based on geographical location at the time of purchase, not on residential status.
Design principle 1B. Resource boundaries: clear boundaries are present that define a resource system and separate it from the larger biophysical environment.

The physical boundary of this pollutant cannot be separated from a larger biophysical system because GHG emissions become globally mixed in the atmosphere no matter their origin on the planet. The outcomes of these pollutants can therefore be felt across large spatial distances (U.S. EPA 2013). Therefore, based on the Cox et al. (2010) reformulation, this design principle is absent in the BC carbon tax governance system.

Design principle $2 A$. Congruence with local conditions: appropriation and provision rules are congruent with local social and environmental conditions.

According to CPR theory, rules should be adaptable to local resource conditions, such as changes in availability of the physical resource, or released quantity of a pollutant, in space and time (Cox et al. 2010). In this case study, the rules on appropriation are lenient; there is no hard limit on the emissions a household or organization may produce but consumers must pay the tax to produce GHG emissions, i.e., consume carbon-based fuels. As for the provision rules, they take the form of tax rates as a tool to regulate the GHG emissions. To achieve congruence between these rules and the local conditions, the tax rate should match the actual volume of carbon emitted, and should be modified according to the changes in carbon emissions through time and space (Cox et al. 2010).

The carbon tax does not explicitly state how the tax rate will change according to the levels of emissions through time; this is left to the discretion of the government based on "whether its GHG emissions targets are being met, the impacts other carbon policies are having, the actions other government are taking, as well as general advice offered by its Climate Action Team" (Sumner et al. 2009:16). As for spatial congruence between the rules and local resource conditions, this would imply a tax rate that changes according to the emissions level of the different regions in $\mathrm{BC}$, which is unlikely to occur because of the practical challenges of implementing a local, as opposed to a provincial, tax rate.

Although not explicitly stated in the legislation, temporal congruence with the volume of carbon-emissions can be achieved. The carbon tax is still in its infancy but this seems to have been achieved thus far; according to the 2014 progress report, BC emissions targets were met hence the government has decided to maintain the current tax rate (BC Government 2014a). However, since the carbon tax leaves temporal congruence to the discretion of the government and spatial congruence is unlikely, we conclude that this design principle is only moderately present.

Design principle $2 B$. Appropriation and provision: the benefits obtained by users from a common-pool resource (CPR), as determined by appropriation rules, are proportional to the amount of inputs required in the form of labor, material, or money, as determined by provision rules.

For CPR management success, the cost of investing time or money in an activity should be less than the benefits from cooperation. Perception of fairness on behalf of users is important (Cox et al. 2010) because equality and rewards for contributions foster collective efforts (Wilson et al. 2013). BC's carbon tax policy acknowledges its disproportionate impacts on certain sectors (e. 
g., less access to public transit in rural areas) and segments of the population (e.g., low-income individuals) with an array of credits, rebates, and exceptions such as the low income climate action tax credit and the northern and rural homeowner benefit (Ministry of Finance 2013, BC Government 2014b).

The carbon tax cannot be fully congruent, however, because of the spatial mismatch between its social and ecological boundaries; users can incur costs for pollutants being emitted outside of BC, and out-of-province users can benefit from the efforts of $\mathrm{BC}$ residents. Thus, this principle is only moderately present.

\section{Design principle 3. Collective-choice arrangements: most individuals affected by the operational rules can participate in modifying the operational rules.}

Users should have a say in the creation of the rules for CPR management. This will help find mutually acceptable rules and is likely to increase compliance with these rules (Tucker 1999, Wilson et al. 2013). According to CPR theory, "A lack of a functional collective-choice arrangement is frequently correlated with CPR management failure" (Cox et al. 2010). The carbon tax is under the control of a provincial government, which has exclusive powers to establish taxation within the province. Although only periodically, the user group in BC has multiple ways to influence the processes that determines how the carbonbased fuels are governed. They can choose to elect the political leaders they feel will best address their concerns regarding the carbon tax through a general election process every four years. Unlike other Canadian provinces, citizens in $\mathrm{BC}$ may also bring issues forward through voter initiatives, which, if successful, require a bill to be considered by the legislature (Elections $\mathrm{BC}$ [date unknown]). Furthermore, over 2000 submissions from the public were made to the BC Ministry of Finance during a recent carbon tax review (BC Government 2013a). Therefore we conclude that this design principle is present.

Design principle 4A. Monitoring users: monitors who are accountable to the users monitor the appropriation and provision levels of the users.

Monitoring of user behavior, i.e., appropriation and provision, should be completed either by the users themselves, by an organization, or by a paid employee, e.g., a guard, that is held accountable to the users (Cox et al. 2010). Monitoring of the users helps detect noncompliance at early stages (Wilson et al. 2013). Carbon tax compliance is monitored. Retail dealers, i.e., those who sell fuel, must collect the carbon tax at the time of sale and remit that tax to the government (BC Government 2014c). Failure to collect taxes is monitored through inspection, audit, or examination, and the associated penalties are described under section 47 of the Carbon Tax Act (BC Government 2014c). The provincial government, who also receive the remitted taxes from fuel retailers, monitors compliance in this governance system. These are functions of normal government operation, and as such are accountable through standard institutions of democracy. However, appropriator behavior in this governance system is only partially monitored. Carbon-fuel consumption is not explicitly monitored but it is assumed that any changes in the $\mathrm{BC}$ carbonemissions are caused by changes in the appropriation levels, i.e., user behavior. Because there is no explicit monitoring of consumption, this principle is only moderately present.
Design principle 4B. Monitoring the resource: monitors who are accountable to the users monitor the condition of the resource. It is important to monitor the environment, i.e., physical resource conditions, to adapt the rules accordingly and manage the resources sustainably (Cox et al. 2010). Monitoring of the resource is not prescribed in the Carbon Tax Act itself but is required through other policies enacted by the $\mathrm{BC}$ government. The carbon tax is part of the Climate Action Plan, a larger provincial campaign to address climate change (BC Government 2008), which specifies that the government must monitor provincial GHG emissions and issue a public report every two years (BC Government 2013b). The report must indicate the current levels of emissions, a comparison between these levels and the targets set in the Greenhouse Gas Reduction Targets Act, and the plans for a continued progress toward these targets (BC Government $2014 c$ ). The stated BC targets are $80 \%$ reduction in GHGs by 2050 and $33 \%$ reduction by 2020 compared to 2007 levels (Ministry of Finance 2014), with interim targets of $18 \%$ by 2016 and $6 \%$ by 2012 (BC Government $2014 d$ ). The first progress report came out in 2012, reporting on the years 2007 to 2010, and indicates that GHG emissions decreased by $4.5 \%$ during that period (BC Government 2012). In 2014, the BC government issued a second report indicating that $\mathrm{GHG}$ were $6 \%$ below the 2007 levels and that the 2012 interim target had been met (BC Government 2014a). As is the case for the previous design principle (4A), monitors who collect measurements on GHG emissions are held accountable to the users. Because the BC government requires monitoring of the resource, we conclude that this design principle is present.

Design principle 5. Graduated sanctions: appropriators who violate operational rules are likely to be assessed graduated sanctions (depending on the seriousness and the context of the offense) by other appropriators, by officials accountable to the appropriators, or by both.

Sanctions should increase incrementally by the severity of the offence and/or the number of offences, which will deter overexploitation and encourage overall compliance (Cox et al. 2010). Noncompliance with the carbon tax refers to failure to collect or remit the tax to the government. Sanctions, i.e., penalties, are detailed in the Carbon Tax Act (BC Government 2014c). The Act is not particularly specific, only delineating maximum penalties in terms of fines and jail time, but the court system could, and probably would, increase the individual penalty for each repeat offense, i.e., graduated sanctions, within these limits. This process is standard in the legal systems of democratic societies. However, to deter overexploitation, graduated sanctions aimed at reducing carbon-based fuel consumption should be considered in addition to sanctions for noncompliance with the tax.

A carbon tax might be conceived of as setting the appropriation limit at 0 , and then sanctioning everyone who exceeds that limit by taxing them for each unit they appropriate. This could be considered a graduated sanction because individuals need to pay for each unit they appropriate over the limit. Further graduation would imply a tax that rises with the level of appropriation, e.g., an organization might pay $\$ 10$ per tonne for the first 100 tonnes, and then $\$ 20$ per tonne for the next 100. However, this type of sanction would be administratively impossible for large-scale pollution issues. More generally, having incrementally increasing 
sanctions based on the number of offenses could imply a tax that increases over time, which would incentivize people to mitigate early. This is what the BC carbon tax has done from 2008-2012. This same principle could also suggest a tax that automatically increases if the provincial emissions targets are not met (see Sumner et al.2009), which might make sense in terms of achieving emissions goals (see design principle 2A). We conclude that, because no changes to the tax rate are explicitly linked to the resource appropriation level (or overexploitation), this design principle is only moderately present.

Design principle 6. Conflict-resolution mechanisms: appropriators and their officials have rapid access to low-cost local arenas to resolve conflicts among appropriators or between appropriators and officials.

Because the carbon tax is a broad-based policy instrument that applies to everyone, conflicts are unlikely to arise on an individual level, but fairness and public input (see principles 2B and 3) are still important. Any legal conflicts between the government and the taxpayers, if they did arise, would be resolved by Canada's system of justice. Therefore, this design principle is present.

Design principle 7. Minimal recognition of rights to organize: the rights of appropriators to devise their own institutions are not challenged by external governmental.

Local authority should be favored over external authority to help adapt the rules to local conditions (Wilson et al. 2013). In our case study, initiatives at the local level are strongly encouraged (e.g., see BC Climate Action Charter Pledge under Design principle 8). However, the users' rights to organize do not supersede the top-down approach of the carbon tax because the $\mathrm{BC}$ government has legislative authority to control taxation within the province. Still, this principle does not imply any obvious alternative, i.e., it would not be appropriate to suggest that individual communities set their own tax rates. We conclude that although this design principle is absent, this aspect of the carbon tax policy is adequate as it is.

Design principle 8. Nested enterprises: appropriation, provision, monitoring, enforcement, conflict resolution, and governance activities are organized in multiple layers of nested enterprises. Coordination and complementarity between the groups becomes important when the resource is part of a larger system (Wilson et al. 2013). This design principle is especially important when there is a mismatch between user boundaries and ecological resource boundaries (Cox et al. 2010). It can be achieved through horizontal and vertical linkages between community-level organizations and/or government agencies. The carbon tax is not explicitly part of a system of nested enterprise. However, there are vertical linkages between provincial and municipal institutions as initiated through the Climate Action Plan. The BC Climate Action Charter Pledge was put in place by the provincial government to work in collaboration with the municipal governments, each in their respective jurisdictions. Over 125 municipalities have signed the Charter and agreed to reduce their GHG emissions through the implementation of programs, policies, and legislative actions (BC Government 2008), though such activities may not be related to the tax itself. This allows for collaborative efforts aimed at reducing carbonbased fuel usage. This design principle is present at the provincial level; however, linkages are missing at the national and global level, which would make it more aligned with the physical boundaries of this resource. As such, we conclude that nested enterprises are only moderately present.

\section{Outcomes}

As a reminder, the design principles are general guidelines for successful management of CPRs. As such, we propose that the outcome of the carbon tax might be affected by the presence or absence of the design principles. Referring back to our research questions, most of the design principles are present or at least moderately present in our case study (see Table 1). Furthermore, although it is still in its infancy, the carbon tax has been successful in achieving a reduction in carbon emissions thus far (see BC Government 2012, 2014a, Elgie and McClay 2014).

Table 1. Presence of the design principles in the British Columbia carbon tax case study.

\begin{tabular}{ll}
\hline \hline Design principle & Presence of the design principle \\
\hline 1A. User boundaries & Present \\
1B. Resource boundaries & Absent \\
2A. Congruence with local & Moderately present \\
conditions & \\
2B. Appropriation and provision & Moderately present \\
3. Collective-choice arrangements & Present \\
4A. Monitoring users & Moderately present \\
4B. Monitoring the resource & Present \\
5. Graduated sanctions & Moderately present \\
6. Conflict-resolution mechanism & Present \\
7. Minimal recognition of rights to & Absent \\
organize & \\
8. Nested enterprises & Moderately present \\
\hline
\end{tabular}

\section{DISCUSSION}

The BC carbon tax presents implications for larger-scale pollution problem and policy analysis. For each of the design principles, we compare our case study with past research looking at the applicability of the design principles for large-scale CPRs and pollution problems. We then compare any insights to those already generated by existing carbon tax analyses.

\section{Applicability to large-scale common-pool resources and pollution problems}

We argue that our case study strengthens existing support for the applicability the design principles to large-scale CPR management, as expressed by other authors (e.g., Epstein et al. 2014, Fleischman et al. 2014). Fleischman et al. (2014) found that the following design principles were present in the most successful CPR management systems: clearly defined social boundaries (1A), clearly defined ecological boundaries (1B), congruence between appropriation and provision rules and local conditions (2A), and monitoring of CPR resource conditions (4B). In addition, nested enterprises (8) were found to be absent in all the unsuccessful cases. The authors conclude that nested enterprise might be the most critical principle for large-scale CPR management systems. In addition, Fleischman et al. (2014) suggest that some design principles might need to be reconceptualized to apply to large-scale CPR systems. More specifically, principles of bottom-up organization, i.e., accountability of monitors and minimum recognition of rights 
to self-organize, were not supported in the five case studies, which suggest they might be substitutable through other means, such as the political system (Fleischman et al. 2014).

Only two of the design principles are absent (1B and 7) while some are relatively weak $(2 \mathrm{~A}, 2 \mathrm{~B}, 4 \mathrm{~A}, 5,8)$ in our case study. When paralleled with other successful large-scale CPR management institutions, our case study provides support for the applicability of the design principles. Other than clearly defined resource boundaries (1B), all five facilitating design principles (1A, 2A, $4 \mathrm{~B}, 8)$ found in Fleischman et al. (2014) are present in our case study, to some extent. The carbon tax case study also supports the claim by Fleischman et al. (2014) that principles of bottomup organization can be substituted by other political dynamics, such as provincial government processes (i.e., 4A, 4B, and 7).

However, our case study does not provide support for the suggestion, by Epstein et al. (2014), that clear resource boundaries (1B) and graduated sanctions (5) play a lesser role in pollution CPRs. Their case study is, in many ways, comparable to ours because it studies a highly mobile pollutant. The authors bring forth the idea that this governance system might have been more successful because clear resource boundaries were absent; this might have engendered a greater sense of urgency to act on a global scale and thus resulted in better management of the pollutants. In our case, the lack of clear boundaries has not succeeded in motivating a more global management of the pollutant, possibly because of the spatial mismatch between social and ecological boundaries. When compared to the BC carbon tax, the social boundaries of the Montreal Protocol system were more closely matched to the ecological boundaries, which may have helped mitigate the potential effect of weak resource boundaries. As for graduated sanctions (5), Epstein et al. (2014) recognize their absence but do not feel it was needed in this governance system because compliance was high. However, we find no reason to suggest, based on the BC carbon tax case study, that graduated sanctions are less important for pollution problems. On the contrary, increasing graduated sanctions efforts might complement efforts to manage GHG over time.

\section{Potential improvements}

The theory behind the design principles suggests the following adjustments might improve the carbon tax success as a tool for carbon-emissions management. The BC carbon tax policy attempts to achieve congruence between benefits and inputs of users (2B) by imposing a limit on free riding within its social boundaries. However, because there is a mismatch between the social boundaries of the tax and the biophysical resource boundaries (1B), it is limited in its ability to do so. Users located within the provincial borders of this policy will incur costs for pollutants being emitted outside of their social boundaries even if they have reduced their own emissions levels. Because the pollutant in our case study is highly mobile, the governance system cannot exclude outside users from emitting the pollutants and depleting the resource system. It can only reduce free riding, within its social boundaries, by ensuring that each user pays a price based on carbon-based fuel usage. Because of this mismatch between the social and resource boundaries, the moderate presence of nested enterprise (8) is possibly the most important design principle to consider for this case study. The $\mathrm{BC}$ carbon tax would benefit from more horizontal linkages with other provinces, vertical with the federal government, and internationally, which would mitigate free riding (2B). Like ozone depleting substances, a form of pollutant that is highly mobile, GHGs might require "global participation and mechanisms to ensure participants [can] not simply offshore their emissions to a few non-participating nations" (Epstein et al. 2014:347). This might allow for significant cumulative reductions in global GHG emissions. The broader problem will not be solved unless a more nested enterprise can be established. Although this is very difficult to do, especially at the international level, BC could certainly take a more active role in encouraging other provinces or the federal government, or the international community, to complement its existing system. The literature on polycentricity (e.g., Ostrom 2012) suggests that this sort of multilevel collaborative approach is necessary.

Furthermore, this governance system assumes, and is probably right to do so, that changes in carbon emissions are caused by changes in appropriation levels. Even so, this governance system might benefit from closer monitoring of the appropriation levels (4A). Closer monitoring, e.g., interviews or surveys to determine the motivation and decision structures of users, could point to obstacles preventing certain users from reacting to the economic incentive provided by the tax and reducing their carbon-based fuel consumption. Furthermore, based on our analysis of the graduated sanctions (5) design principle, one form of graduated sanction would be to continue increasing the tax over time, i.e., more specifically committing to tax increases if the emission reduction targets are not met (see 2A). This should further increase the governance system's ability to successfully manage the resource through time based on the established targets. Overall, congruence between appropriation and provision (2A) will be easier to achieve if appropriation is monitored and graduated sanctions are re-enforced.

\section{Revisiting the design principles}

We believe that the principles can be helpfully applied for larger scale CPR management. However, the Cox et al. (2010) description of the design principles for community-based CPR management might need to be modified. More specifically, for large-scale CPR management, many design principles can be substituted by complementary programs or policies and thus need to be critically examined at a broader scale. For example, the carbon tax was implemented as part of a larger BC Climate Action Plan (BC Government 2008), which covers GHG monitoring (4B) and tax credits (2B). Furthermore, as mentioned by Fleishman at al. (2014) and supported in our case study, principles of bottomup organization $(3,4 \mathrm{~A}, 4 \mathrm{~B}, 6$, and 7 ) might be substitutable through existing institutions of the jurisdiction, e.g., democratic elections or the justice system. The presence of these design principles by substitution reinforces the necessity of having an elaborate horizontal and vertical system of nested enterprises (8) for larger-scale CPR management.

\section{Contributions to policy analysis}

The use of the design principles in this alternative policy evaluation has provided some novel insight into the effectiveness of the $\mathrm{BC}$ carbon tax. In particular, more aggressive negotiation of nested enterprise (interjurisdictional cooperation) is recommended. Further reductions in the use of carbon-based fuels might be achieved if the $\mathrm{BC}$ government continues to 
gradually increase the tax based on whether or not the targets have been met, and thus provides a form of graduated sanctions. These are, of course, merely suggestions for positive directions in which the carbon tax policy might move. We do not yet have data to prove that such improvements will work, but the foundation of data in the CPR literature suggests that they might; this is a contribution in itself. In addition, many of the design principles reinforce the findings from existing policy evaluations: equity of social impacts should be considered, those affected should be consulted, and it should be integrated with other policy measures (BC Government 2013a, Elgie and McClay 2013, Rhodes and Horne 2013).

Overall, the design principles support the conclusions of the policy evaluations that the carbon tax is effective because it conforms to many of the best practices identified in the CPR literature. We think our assessment provides support for adding the design principles to the list of tools used to conduct policy analyses. Although the three reports suggested different opportunities for improvement in the tax, they are only comprehensive, i.e., fully addressing effectiveness, efficiency, and equity, when considered together. To the contrary, the design principles allow us to not only reach similar conclusions as the traditional policy analyses, e.g., pointing to the same issues of effectiveness, as in principle 4A (although, this is no substitute for actually measuring the relevant variables), but also make further recommendations, e.g., nested enterprise, graduated sanctions. Such suggestions are based on a broader conceptualization of the problem rooted in CPR theory, e.g., the nested enterprises recommendation acknowledges that there are system-wide problems that must be addressed, and address the tendency of climate policy evaluation to focus on narrow goals (see Huitema et al. 2011).

\section{CONCLUSION}

In this paper we assessed the long-term viability of the $\mathrm{BC}$ carbon tax using CPR design principles (see Cox et al. 2010), a novel application of such principles to environmental policy. We found that the design principles can be applied to analyze environmental policy and suggested that most of them were relevant to larger scale air pollution problems. With regard to the carbon tax, our findings support previous policy evaluations and suggest that closer monitoring of user behavior, further increases of the tax over time, continuous consideration of social impact fairness, ongoing public consultation, and pursuing efforts for a more elaborate system of nested enterprises and interjurisdictional cooperation could increase the long-term success of the $\mathrm{BC}$ carbon tax. We also found that the design principles allowed us to more comprehensively reach conclusions regarding the broader effectiveness of the tax when compared to existing policy analyses.

We hope to have contributed to theory about policy evaluation and CPRs. Traditionally, climate policy evaluation has lacked reflexivity and been fairly unsystematic (Huitema et al. 2011). We suggest that CPR theory, which is based on strong theoretical principles, has been vetted, and encourages reflexivity, will be able to address those limitations. However, we reviewed only one context, the BC carbon tax. Further research is needed to determine the relevance of the design principles for policy analysis of other CPRs such as land and water. On the other hand, the
CPR management principles have been criticized as only being relevant to resources, as opposed to pollutants, at the community level. We hope that they will, indeed, prove to be relevant for a more complex pollutant that is part of a broader system. Furthermore, our analysis only applies the existing design principles in one new large-scale context. Although it is now starting to receive more scholarly attention, the applicability of Ostrom's design principles for large-scale CPRs is still relatively new and should be studied further. Some of the design principles might need to be reconceived for large-scale application and for application to pollution problems. Such a consideration is another potential avenue for future research. The results of multiple case studies could possibly generate a slightly different list of principles specifically for large-scale pollutants.

Responses to this article can be read online at: http://www.ecologyandsociety.org/issues/responses. $\mathrm{php} / 7519$

\section{Acknowledgments:}

The authors would like to thank Dr. Natalie Ban for her edits and suggestions, as well as two anonymous reviewers.

\section{LITERATURE CITED}

Agrawal, A. 2001. Common property institutions and sustainable governance of resources. World Development 29:1649-1672. http://dx.doi.org/10.1016/S0305-750X(01)00063-8

Agrawal, A. 2002. Common resources and institutional sustainability. Pages 41-86 in E. Ostrom, T. Dietz, N. Dolšak, P. C. Stern, S. Stonich, S., and E. U. Weber, editors. The drama of the commons. National Academy Press, Washington, D.C., USA.

Baxter P., and S. Jack S. 2008. Qualitative case study methodology: study design and implementation for novice researchers. Qualitative Report 13:544-559.

British Columbia (BC) Government. 2008. Climate action plan. BC Government, Victoria, BC, Canada. [online] URL: http:// www.livesmartbc.ca/attachments/climateaction plan web.pdf

British Columbia (BC) Government. 2012. Making progress on B. C.'s climate action plan. BC Government, Victoria, BC, Canada. [online] URL: http://www.env.gov.bc.ca/cas/pdfs/2012-Progressto-Targets.pdf

British Columbia (BC) Government. 2013a. Carbon tax review. BC Government, Victoria, BC, Canada. [online] URL: http:// www.fin.gov.bc.ca/tbs/tp/climate/Carbon Tax Review Topic Box. pdf [Accessed October 12, 2013].

British Columbia (BC) Government. 2013b. Greenhouse Gas Reduction Targets Act. BC Government, Victoria, BC, Canada. [online] URL: http://www.bclaws.ca/EPLibraries/bclaws new/ document/ID/freeside/00_07042_01

British Columbia (BC) Government. 2014c. Carbon Tax Act. BC Government, Victoria, BC, Canada. [online] URL: http://www. bclaws.ca/EPLibraries/bclaws_new/document/ID/freeside/00_08040_01 
British Columbia (BC) Government. 2014a. Climate action in British Columbia: 2014 progress report. BC Government, Victoria, BC, Canada. [online] URL: http://www.env.gov.bc.ca/cas/ pdfs/2014-Progress-to-Targets.pdf

British Columbia (BC) Government. 2014d. Climate action legislation. BC Government, Victoria, BC, Canada. [online]

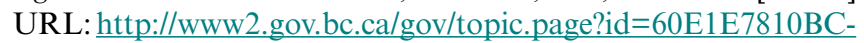
$\underline{\text { 145C6B6FC00EE31F41EC5 }}$

British Columbia (BC) Government. 2014b. Low income climate action tax credit. BC Government, Victoria, BC, Canada. [online] URL: http://www2.gov.bc.ca/gov/topic.page?id= E9258ADE1AE3423080A1B2674F4EAABD

British Columbia (BC) Stats. 2013. Population estimates. BC Government, Victoria, BC, Canada. [online] URL: http://www. bcstats.gov.bc.ca/StatisticsBySubject/Demography/PopulationEstimates. $\underline{\operatorname{aspx}}$

Cox, M., editor. 2014. Understanding large social-ecological systems: introducing the SESMAD project. International Journal of the Commons 8(2). [online] URL: http://www.thecommonsjournal. org/index.php/ijc/article/view/406

Cox, M., G. Arnold, and S. Villamayor-Tomás. 2010. A review of design principles for community-based natural resource management. Ecology and Society 15(4): 38. [online] URL: http:// www.ecologyandsociety.org/vol15/iss4/art38/

Elections BC. [date unknown]. Initiative. Elections BC, Victoria, BC, Canada. [online] URL: http://www.elections.bc.ca/index. php/referenda-recall-initiative/initiative/

Elgie, D. S., and J. McClay. 2013. BC's carbon tax shift after five years: results. Sustainable Prosperity, University of Ottawa, Ottawa, Ontario, Canada. [online] URL: http://www. sustainableprosperity.ca/d11026\&display

Epstein, G., I. Pérez, M. Schoon, and C. L. Meek. 2014. Governing the invisible commons: ozone regulation and the Montreal Protocol. International Journal of the Commons 8:337-360.

Fleischman, F. D., N. C. Ban, L. S. Evans, G. Epstein, G. GarciaLopez, and S. Villamayor-Tomas. 2014. Governing large-scale social-ecological systems: lessons from five cases. International Journal of the Commons 8:428-456.

Goodin, R. E., editor. 1998. The theory of institutional design. Cambridge University Press, Cambridge, UK. http://dx.doi. org/10.1017/cbo9780511558320

Hardin, G. 1968. The tragedy of the commons. Science 162:1243-1248. http://dx.doi.org/10.1126/science.162.3859.1243

Howlett M., A. Perl, and M. Ramesh, editors. 2009. Studying public policy: policy cycles and policy subsystems. Third Edition. Oxford University Press, Oxford, UK.

Huitema, D., A. Jordan, E. Massey, T. Rayner, H. van Asselt, C. Haug, R. Hildingsson, S. Monni, and J. Stripple. 2011. The evaluation of climate policy: theory and emerging practice in Europe. Policy Sciences 44:179-198. http://dx.doi.org/10.1007/ $\underline{\text { s11077-011-9125-7 }}$
Intergovernmental Panel on Climate Change (IPCC). 2013. Summary for policymakers. In Climate Change 2013: the physical science basis. Contribution of Working Group I to the Fifth Assessment Report of the Intergovernmental Panel on Climate Change. T. F. Stocker, D. Qin, G.-K. Plattner, M. Tignor, S.K. Allen, J. Boschung, A. Nauels, Y. Xia, V. Bex, and P.M. Midgley, editors. Cambridge University Press, Cambridge, UK. [online] URL: http://www.ipcc.ch/report/ar5/wg1/

Litman, T. 2009. Evaluating carbon taxes as an energy conservation and emission reduction strategy. Transportation Research Record 2139:125-132. http://dx.doi.org/10.3141/2139-15

Lockyer, S., A. Coffey, P. Atkinson, J. Fielding, A. Strauss, A. Strauss, and J. Corbin. 2004. Coding qualitative data. Pages 138-139 in M. S. Lewis-Beck, A. Bryman, and T. F. Liao, editors. The SAGE encyclopedia of social science research methods. Sage, Thousand Oaks, California, USA. http://dx.doi. org/10.4135/9781412950589.n130

Ministry of Finance. 2013. Myths and facts about the carbon tax. BC Government, Victoria, BC, Canada. [online] URL: $\underline{\text { http:// }}$ www.fin.gov.bc.ca/tbs/tp/climate/A6.htm

Ministry of Finance. 2014. Budget and fiscal plan 2008/09 2010/11. BC Government, Victoria, BC, Canada. [online] URL: http://www.bcbudget.gov.bc.ca/2008/bfp/2008 Budget Fiscal Plan. pdf

Ostrom, E. 1990. Governing the commons: the evolution of institutions for collective action. Cambridge University Press, Cambridge, UK. http://dx.doi.org/10.1017/cbo9780511807763

Ostrom, E. 2009. A polycentric approach for coping with climate change. Policy Research Working Chapter 5095. World Bank, Washington, D.C., USA. http://dx.doi.org/10.1596/1813-9450-5095

Ostrom, E. 2010. Polycentric systems for coping with collective action and global environmental change. Global Environmental Change 20:550-557. http://dx.doi.org/10.1016/j.gloenvcha.2010.07.004

Ostrom, E. 2012. Nested externalities and polycentric institutions: Must we wait for global solutions to climate change before taking action at other scales? Economic Theory 49:353-369 http://dx.doi. org/10.1007/s00199-010-0558-6

Pal, L. A. 1987. Public policy analysis: an introduction. Methuen, Agincourt, Ontario, Canada.

Rhodes, E., and M. Horne. 2013. Assessing British Columbia's carbon tax design: public and stakeholder perspectives. Pages 159-178 in L. Kreiser, D. Duff, J. E. Mine, H. Ashiabor, editors. Market based instruments. Edward Elgar, Cheltenham, UK. http://dx.doi.org/10.4337/9781782548720.00021

Rivers, N., and B. Schaufele. 2013. Salience of carbon taxes in the gasoline market. Social Science Research Network, Rochester, New York, USA. [online] URL: http://papers.ssrn.com/ $\underline{\text { abstract }=2131468}$

Rowland, M. 2005. A framework for resolving the transboundary water allocation conflict conundrum. Groundwater 43:700-705. http://dx.doi.org/10.1111/j.1745-6584.2005.00066.x 
Sodero, S. 2011. Policy in motion: reassembling carbon pricing policy development in the personal transport sector in British Columbia. Journal of Transport Geography 19:1474-1481. http:// dx.doi.org/10.1016/j.jtrangeo.2011.09.001

Sumner, J., L. Bird, and H. Smith. 2009. Carbon taxes: a review of experience and policy design considerations. U.S. Department of Energy, National Renewable Energy Laboratory, Golden, Colorado, USA. http://dx.doi.org/10.2172/970341

Tellis, W. 1997. Application of a case study methodology. Qualitative Report 3:1-19.

Thiel, A. 2014. Rescaling of resource governance as institutional change: explaining the transformation of water governance in southern Spain. Environmental Policy and Governance 24:289-306. http://dx.doi.org/10.1002/eet.1644

Tucker, C. 1999. Common property design principles and development in a Honduran community. Praxis: The Fletcher Journal of Developmental Studies 14:1-23. [online] URL: http:// fletcher.tufts.edu/Praxis/Archives/ /media/Fletcher/Microsites/praxis/ xv/Tucker.pdf

United States Environmental Protection Agency (U.S. EPA). 2013. Climate change indicators in the United States: greenhouse gases. U.S. EPA, Washington, D.C., USA. [online] URL: http:// www.epa.gov/climatechange/science/indicators/ghg/

Vatn, A. 2005. Rationality, institutions and environmental policy. Ecological Economics 55:203-217. http://dx.doi.org/10.1016/j. ecolecon.2004.12.001

Villamayor-Tomas, S., F. D. Fleischman, I.P. Ibarra, A. Thiel, and F. van Laerhoven. 2014. From Sandoz to salmon: conceptualizing resource and institutional dynamics in the Rhine watershed through the SES framework. International Journal of the Commons 8:361-395.

Wilson, D. S., E. Ostrom, and M. E. Cox. 2013. Generalizing the core design principles for the efficacy of groups. Journal of Economic Behavior \& Organization 90:S21-S32. http://dx.doi. org/10.1016/j.jebo.2012.12.010

Young, O. 2002. The institutional dimensions of environmental change: fit, interplay, and scale. MIT Press, Cambridge, Massachusetts, USA.

Young, O. R., E. F. Lambin, F. Alcock, H. Haberl, S. I. Karlsson, W. J. McConnell, T. Myint, C. Pahl-Wostl, C. Polsky, P. Ramakrishnan, H. Schroeder, M. Scouvart, and P. H. Verburg. 2006. A portfolio approach to analyzing complex humanenvironment interactions: institutions and land change. Ecology and Society 11(2): 31. [online] URL: http://www.ecologyandsociety. org/vol11/iss2/art31/ 